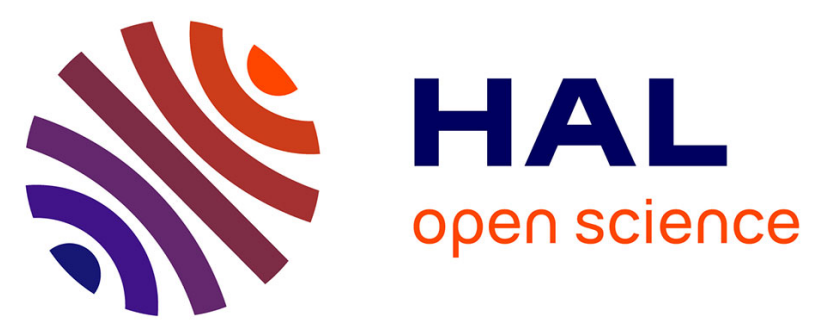

\title{
Bridging the gap between impact assessment methods and climate science
}

Francesco Cherubini, Jan Fuglestvedt, Thomas Gasser, Andy Reisinger,

Otávio Cavalett, Mark A. J. Huijbregts, Daniel J. A. Johansson, Susanne V. Jørgensen, Marco Raugei, Greg Schivley, et al.

\section{To cite this version:}

Francesco Cherubini, Jan Fuglestvedt, Thomas Gasser, Andy Reisinger, Otávio Cavalett, et al.. Bridging the gap between impact assessment methods and climate science. Environmental Science and Policy, 2016, 64, pp.129-40. 10.1016/j.envsci.2016.06.019 . hal-01425092

\section{HAL Id: hal-01425092 \\ https://hal-enpc.archives-ouvertes.fr/hal-01425092}

Submitted on 6 Sep 2021

HAL is a multi-disciplinary open access archive for the deposit and dissemination of scientific research documents, whether they are published or not. The documents may come from teaching and research institutions in France or abroad, or from public or private research centers.
L'archive ouverte pluridisciplinaire HAL, est destinée au dépôt et à la diffusion de documents scientifiques de niveau recherche, publiés ou non, émanant des établissements d'enseignement et de recherche français ou étrangers, des laboratoires publics ou privés. 
3 Francesco Cherubini ${ }^{\mathrm{a}^{*}}$, Jan Fuglestvedt ${ }^{\mathrm{b}}$, Thomas Gasser ${ }^{\mathrm{c}, \mathrm{d}}$, Andy Reisinger $^{\mathrm{e}}$, Otávio Cavalett ${ }^{\mathrm{f}}$, Schivley ${ }^{1,}$, Anders Hammer Strømman ${ }^{a}$, Katsumasa Tanaka ${ }^{m}$, Annie Levasseur $^{n}$

6

${ }^{a}$ Industrial Ecology Programme, Department of Energy and Process Engineering, Norwegian University of Science and Technology (NTNU), Trondheim, Norway

${ }^{b}$ Center for International Climate and Environmental Research - Oslo (CICERO), Oslo, Norway ${ }^{c}$ Laboratoire des Sciences du Climat et de l'Environnement (LSCE), Institut Pierre-Simon Laplace (IPSL), CEACNRS-UVSQ, 91191 Gif-sur-Yvette Cedex, France

${ }^{\mathrm{d}}$ Centre International de Recherche sur l'Environnement et le Développement (CIRED), CNRS-PontsParisTechEHESS-AgroParisTech-CIRAD, 94736 Nogent-sur-Marne Cedex, France

${ }^{\mathrm{e}}$ New Zealand Agricultural Greenhouse Gas Research Centre, Palmerston North 4442, New Zealand ${ }^{f}$ Laboratório Nacional de Ciência e Tecnologia do Bioetanol (CTBE/CNPEM), Campinas, São Paulo, Brazil ${ }^{8}$ Department of Environmental Science, Institute for Water and Wetland Research, Radboud University, Nijmegen, The Netherlands

${ }^{\mathrm{h}}$ Dutch Environmental Assessment Agency, Bilthoven, The Netherlands ${ }^{\mathrm{i}}$ Division of Physical Resource Theory, Department of Energy and Environment, Chalmers University of Technology, Gothenburg, Sweden ${ }^{j}$ ALECTIA A/S, Virum, Denmark ${ }^{k}$ Faculty of Technology, Design and Environment, Oxford Brookes University, Wheatley, UK ${ }^{1}$ Civil and Environmental Engineering, Carnegie Mellon University, Pittsburgh, Pennsylvania, United States ${ }^{\mathrm{m}}$ National Institute for Environmental Studies (NIES), Tsukuba, Japan ${ }^{n}$ Polytechnique Montréal, Department of Chemical Engineering, CIRAIG, Montréal, Canada 
Life-cycle assessment and carbon footprint studies are widely used by decision makers to identify climate change mitigation options and priorities at corporate and public levels.

52 Keywords: climate change; emission metrics; life cycle assessment (LCA); global warming 53

These applications, including the vast majority of emission accounting schemes and policy frameworks, traditionally quantify climate impacts of human activities by aggregating greenhouse gas emissions into the so-called $\mathrm{CO}_{2}$-equivalents using the 100 -year Global Warming Potential (GWP100) as the default emission metric. The practice was established in the early nineties and has not been coupled with progress in climate science, other than simply updating numerical values for GWP100. We review the key insights from the literature surrounding climate science that are at odds with existing climate impact methods and we identify possible improvement options. Issues with the existing approach lie in the use of a single metric that cannot represent the climate system complexity for all possible research and policy contexts, and in the default exclusion of near-term climate forcers such as aerosols or ozone precursors and changes in the Earth's energy balance associated with land cover changes. Failure to acknowledge the complexity of climate change drivers and the spatial and temporal heterogeneities of their climate system responses can lead to the deployment of suboptimal, and potentially even counterproductive, mitigation strategies. We argue for an active consideration of these aspects to bridge the gap between climate impact methods used in environmental impact analysis and climate science. potential (GWP). 
Human activities perturb the climate system through a variety of forcing agents. Over the industrial era, the total anthropogenic radiative forcing, a measure of the net energy imbalance of the Earth caused by a forcing agent, is 2.29 [1.13 to 3.33$] \mathrm{W} \mathrm{m}^{-2}$ [1]. The major contributors are carbon dioxide $\left(\mathrm{CO}_{2}\right)$ and methane $\left(\mathrm{CH}_{4}\right)$ emissions, which are responsible for about $1.68 \pm 0.17 \mathrm{~W} \mathrm{~m}^{-2}$ and $0.97 \pm 0.17 \mathrm{~W} \mathrm{~m}^{-2}$, respectively [1]. The net contribution from so-called Near-Term Climate Forcers (NTCFs), that is, species with an atmospheric lifetime of less than about one year, is estimated to be a slight negative forcing (cooling) of $-0.06 \mathrm{~W} \mathrm{~m}^{-2}[1]$, with large uncertainty bounds largely due to the lack of scientific understanding of aerosol-cloud interactions [2]. The contributions from the direct forcing effect of single NTCFs range between $-0.41 \pm 0.20 \mathrm{~W} \mathrm{~m}^{-2}$ for sulphur oxides $\left(\mathrm{SO}_{\mathrm{x}}\right)$ emissions and $+0.64[+0.25$ to +1.09$] \mathrm{W} \mathrm{m}^{-2}$ for black carbon $(\mathrm{BC})$ emissions [1]. The radiative forcing values from historical land use changes for $\mathrm{CO}_{2}$ and surface albedo (the ratio between reflected and incident solar radiation at the surface) are of the same order of magnitude but opposite sign, with a warming effect of 0.17 to $0.51 \mathrm{~W} \mathrm{~m}^{-2}$ for $\mathrm{CO}_{2}\left(1850_{-}\right.$ $2000)$ and a cooling effect of $-0.15 \pm 0.10 \mathrm{~W} \mathrm{~m}^{-2}$ for surface albedo changes (1750-2011)

[1]. The net effect from changes in emissions of biogenic volatile organic compounds (BVOCs) associated with this land use change is estimated to be an additional cooling contribution of $-0.11 \pm 0.17 \mathrm{~W} \mathrm{~m}^{-2}(1850-2000)[3]$.

Life cycle assessment (LCA) and carbon footprints are largely used to attribute climate change impacts to specific human activities like products, technological systems, or sectors [4]. Decision and policy makers widely rely on the outcomes from comparative climate impact analyses to promote mitigation options, and to design strategies for sustainable production and consumption at a public or corporate level. The most common approach is to aggregate emissions of well-mixed greenhouse gases to so-called " $\mathrm{CO}_{2}$-equivalents" 
using the 100-year global warming potential (henceforth GWP100) as the default emission metric. A similar procedure is frequently applied in international agreements, like the Kyoto protocol, the Intended Nationally Determined Contributions (INDCs) for mitigation obligations to 2030 and climate-oriented policy directives, such as those regulating the climate impacts of specific sectors. This practice does not take into account the impacts from emissions of NTCFs or biophysical factors arising from changes in land cover. It also overlooks the temporal and spatial heterogeneities of the climate system response to different forcing agents, and the consideration of emission metrics alternative to GWP100. Studies that have explored the influence of NTCFs [5, 6], of changes in surface albedo [7, 8], of temporal and spatial impact dynamics [9-11], and of metrics other than GWP100 [5, 1215] on the climate impacts attributed to a specific human activity usually conclude that an international effort on improving existing methods is desirable to prevent the implementation of suboptimal mitigation pathways.

The Life Cycle Initiative under the United Nations Environment Program (UNEP) and the Society of Environmental Toxicology and Chemistry (SETAC) launched the Global Guidance on Environmental Life Cycle Impact Assessment Indicators to revise existing standard methodologies used in environmental impact categories of LCA and footprint studies [16, 17], including climate change. Here, as part of the activities from the Global Warming Task Force, we identify key insights from the climate science related literature that are of relevance for advancing climate impact assessment frameworks.

\section{Life cycle impact assessment and emission metrics}

The life cycle impact assessment phase consists in the conversion of different well-mixed greenhouse gases (WMGHGs) to common units ( $\mathrm{kg} \mathrm{CO}_{2}$-eq) after multiplication of each 
103

104

105

106

107

108

109

110

111

112

113

114

115

116

117

118

119

120

121

122

123

124

125

126

127

emission flow by the respective emission metric, [4]. Emission metrics, which in LCA are usually referred to as characterization factors, are typically simplified measures of the

climate system response to forcing agents and are mostly based on outcomes from physical models of varying complexity linking emissions to impacts [1]. Metrics can be formulated in absolute terms, for instance based on the temporal evolution of a temperature impact, or in relative terms after normalization to a reference gas, usually $\mathrm{CO}_{2}[5,18]$. Different emissions have different climate system responses, and a metric that establishes equivalence with regard to one effect does not usually result in equivalence with regard to other effects.

GWP is an integrative measure defined as the integrated radiative forcing of a gas between the time of emission and a chosen time horizon $(\mathrm{TH})$ relative to that of $\mathrm{CO}_{2}$. The GWP was introduced by the first IPCC assessment report in 1990 with illustrative purposes and, by its own definition, it does not embed any climate system responses or direct link to policy goals [1]. Despite the rather cautious introduction by the IPCC, the United Nations Framework Convention on Climate Change, LCA and the majority of national and corporate emission accounting frameworks started to use this metric without any substantial modifications, with the exception of updating the GWP values according to the successive IPCC reports.

GWP is a metric that aligns well with the general principles of LCA. LCA privileges impacts integrated over time and space under the objective of avoiding burden shifting of impacts [4]. LCA also typically follows a "marginal change" approach, in the sense that an additional amount of a certain pollutant is assumed to introduce very small changes on top of a constant background. This approach allows the assessment of environmental impacts associated with the life cycle impacts of a single unit of a product, which gives only a small contribution to the total impact [19]. Common critiques to GWP concern the fact that, despite its name, it does not equate climate forcing agents on the basis of their effects on surface temperature, nor does it consider them under a specific climate policy target, such 
as the goal to limit warming to 2 degrees above pre-industrial levels [18, 20-22]. The use of a TH of 100 years seems to be the result of an "inadvertent consensus" [23] and it is not

130 directly linked to any particular climate policy objective. There are many emission metrics

131 available from the climate science literature that focus on different characteristics of the

132 climate system response to emissions [12, 18, 20, 21, 24-28]. By targeting different aspects

133 of the climate impact cause-effect chain, such as radiative forcing [29], temperature [26,

134 27], sea level rise [30], precipitation changes [31], or economic dimensions [28], these

135 metrics compare emissions on the basis of their instantaneous [26] or time integrated

136 impacts [25, 27]. They are computed under a constant [1, 24] or changing [18, 32]

137 background climate and can be formulated around a fixed or a target-dependent TH [14,

$13818,33,34]$. A common alternative to GWP is the Global Temperature Change Potential

139 (GTP), which is defined as the impact of a GHG emission pulse on global temperature at the

140 chosen $\mathrm{TH}$, again relative to $\mathrm{CO}_{2}$ [26]. With the exception of some gases with very short

141 lifetimes, values of GTP for a TH of about 40 years are usually similar to those of GWP100

142 [35]. Recently, GWP100 is shown to approximately equate a pulse emission of a cumulative 143 climate pollutant and an indefinitely sustained change in the rate of emission of short-lived

144 forcers, introducing a new application for GWP100 in comparing WMGHGs with different

145 lifetimes [36]. Within a context of emission accounting, some also argue against the practice

146 of aggregating all WMGHGs to common units $[29,37,38]$ and instead explore a multi-

147 basket approach in which gases with similar lifetimes are grouped together [29, 37-41].

148 Metrics that are further down the cause effect chain produce outcomes that are more policy

149 relevant than those based on radiative forcing, but at the same time their embedded

150 uncertainties increase. For instance, uncertainties for GTP are larger than those for GWP,

151 because the latter does not embed the uncertainty of the climate system response.

152 Temperature-based metrics involve a climate model, which can be a simple energy balance 
model [25, 26], a temperature response function [24], or more sophisticated climate models $[18,24,28,42]$, and this generally makes results sensitive to the parameterization of the climate system [1]. Multi-model means are frequently used to mitigate these concerns [24] and to better understand uncertainties [42]. However, the subjective selection of a TH for the different metrics remain the most important factor that determines metrics variability [24], especially for the weight given to forcers with a relatively short lifetime, compared to forcers with long lifetimes [18]. This choice dependence introduces a strong, but often inadvertent and only implicit, value judgement that frequently makes results open to contrary outcomes $[5,15]$.

\section{Well-mixed GHGs (WMGHGs)}

$\mathrm{CO}_{2}, \mathrm{CH}_{4}$, nitrous oxide $\left(\mathrm{N}_{2} \mathrm{O}\right)$, and some groups of halogenated gases have atmospheric lifetimes longer than the hemispheric mixing time (up to a few years). They are generally considered well-mixed because their atmospheric concentration has sufficient time to become nearly uniformly distributed in the troposphere and their radiative forcing patterns are usually independent of the emission location [1]. Table 1 shows a classification of the main WMGHGs grouped by lifetimes, with information about their atmospheric concentration and radiative forcing in 2011, and their radiative efficiency per mass unit atmospheric burden $\left(\mathrm{W} \mathrm{m}^{-2} \mathrm{~kg}^{-1}\right)$. For the purpose of a simple classification, we consider as "short-lived" those WMGHGs, like methane and most hydrofluorocarbons (HFCs) or hydrofluoroethers (HFEs), with atmospheric lifetimes shorter than the response timescale of the climate system, which is typically from two to four decades $[20,43]$. Gases with lifetimes longer than about 50 years are sufficiently long-lived that the climate system has time to 
178 The atmospheric decay of non- $\mathrm{CO}_{2}$ WMGHGs is governed by relatively well-known

179 chemical and physical processes and can be simply described with exponential decay

180 constants corresponding to the respective lifetimes of the gases [45]. The constant decay-

181 time, however, remains an approximation since the lifetime of some gases is actually

182 affected by their own atmospheric concentration, and sometimes by that of other gases. For

183 instance, the atmospheric concentration of $\mathrm{CH}_{4}$ or $\mathrm{N}_{2} \mathrm{O}$ feeds back on their own respective

184 lifetimes [46], $\mathrm{CO}_{2}$ can be produced after oxidation of other carbon-containing gases [1,

185 47], or ozone can cause changes to the global land-carbon sinks [48]. Some short-lived

186 species are thus also responsible of long-term effects through the carbon cycle and climate

187 feedbacks $[1,47,49,50]$.

188 Table 1 WMGHGs grouped by atmospheric lifetimes. For atmospheric concentrations and radiative forcing 189 only the gas listed in Table 8.2 of the WGI $5^{\text {th }}$ IPCC Assessment Report [1] are considered. Information on 190 lifetimes of the gases, atmospheric concentration, radiative forcing and radiative efficiencies are from the $5^{\text {th }}$ IPCC Assessment Report[1].

\begin{tabular}{|c|c|c|c|c|c|}
\hline $\begin{array}{l}\text { Group of } \\
\text { lifetimes }\end{array}$ & Gases & $\begin{array}{c}\text { Lifetime } \\
\text { (years) }\end{array}$ & $\begin{array}{c}\text { Atmospheric } \\
\text { concentrations } \\
\text { in } 2011\end{array}$ & $\begin{array}{c}\text { Radiative } \\
\text { forcing in } 2011 \\
\left(\mathrm{~W} \mathrm{~m}^{-2}\right)\end{array}$ & $\begin{array}{c}\text { Radiative } \\
\text { efficiency } \\
\left(\mathrm{W} \mathrm{m}^{-2} \mathrm{~kg}^{-1}\right)\end{array}$ \\
\hline Years & $\begin{array}{l}\text { Some HCFCs, } \\
\text { HFCs, } \\
\text { Halocarbons, } \\
\text { and HFEs }\end{array}$ & $\begin{array}{c}\text { Between } 1 \\
\text { and } 10\end{array}$ & $\begin{array}{c}21.4 \pm 0.1 p p t \\
\text { HCFC }-141 b\end{array}$ & $\begin{array}{c}0.0034 \mathrm{HCFC}- \\
141 \mathrm{~b}\end{array}$ & $\begin{array}{c}2.05 \mathrm{E}-11 \\
\text { HCFC-141b }\end{array}$ \\
\hline Decades & $\begin{array}{c}\mathrm{CH}_{4}, \mathrm{CFC}- \\
11, \mathrm{CFC}_{-} 113 \text {, } \\
\mathrm{CCl}_{4} \text {, some } \\
\mathrm{HCFCs}, \mathrm{HFCs}, \\
\text { and HFEs }\end{array}$ & $\begin{array}{c}\text { Between } 10 \\
\text { and } 100\end{array}$ & $\begin{array}{c}1803_{ \pm} 2 \mathrm{ppb} \\
\mathrm{CH}_{4}, 238 \pm \\
0.8 \text { ppt CFC- } \\
11\end{array}$ & $\begin{array}{c}0.48 \pm 0.05 \\
\mathrm{CH}_{4}, 0.062 \\
\mathrm{CFC}-11\end{array}$ & $\begin{array}{c}4.65 \mathrm{E}-14 \mathrm{CH}_{4} \\
3.84 \mathrm{E}-11, \mathrm{CFC}- \\
113\end{array}$ \\
\hline Centuries & $\begin{array}{c}\mathrm{N}_{2} \mathrm{O}, \mathrm{HFC}- \\
23, \mathrm{HFC}- \\
236 \mathrm{fa}, \mathrm{HFE}- \\
125, \mathrm{NF}_{3} \\
\text { some CFCs }\end{array}$ & $\begin{array}{c}\text { Between } \\
100 \text { and } \\
1,000\end{array}$ & $\begin{array}{c}324 \pm 0.1 p p b \\
\mathrm{~N}_{2} \mathrm{O}, 528 \mathrm{ppt} \\
\mathrm{CFC}-12\end{array}$ & $\begin{array}{c}0.17 \pm 0.03 \\
\mathrm{~N}_{2} \mathrm{O}, 0.17 \\
\mathrm{CFC}-12\end{array}$ & $\begin{array}{c}3.84 \mathrm{E}-13 \mathrm{~N}_{2} \mathrm{O} \\
4.10 \mathrm{E}-11 \mathrm{CFC}- \\
12\end{array}$ \\
\hline Millennials & Fluorinated & Between & $79 \mathrm{ppt} \mathrm{CF}_{4}$ & $0.0041 \mathrm{SF}_{6}$ & $7.3 \mathrm{E}-11 \mathrm{SF}_{6}$ \\
\hline
\end{tabular}




\begin{tabular}{|l|c|c|c|c|c|}
\hline & $\begin{array}{c}\text { gases }\left(\mathrm{SF}_{6},\right. \\
\left.\mathrm{CF}_{4}, \text { etc. }\right) \\
\mathrm{CFC}-115\end{array}$ & $\begin{array}{c}1,000 \text { and } \\
50,000\end{array}$ & & & \\
\hline Indefinite & $\mathrm{CO}_{2}$ & n.a. & $391 \mathrm{ppm}$ & $1.82 \pm 0.19$ & $1.81 \mathrm{E}-15$ \\
\hline
\end{tabular}

192

193 Among WMGHGs, $\mathrm{CO}_{2}$ represents a special case. Unlike most other agents, it does not

194 decompose through atmospheric chemical reactions, nor it is deposited on the Earth surface,

195 but it is removed from the atmosphere by a variety of processes with different timescales

196 influenced by multiple nonlinear dependencies [24, 51, 52]. For a 100 GtC emission pulse

197 added to a constant $\mathrm{CO}_{2}$ concentration of $389 \mathrm{ppm}, 15-35 \%$ of the perturbation is still

198 found in the atmosphere after a thousand of years; the ocean has absorbed $59 \pm 12 \%$ and the

199 land the remainder $(16 \pm 14 \%)$ [24]. Thereafter $\mathrm{CO}_{2}$ concentration is only removed by

200 ocean-sediment interactions and the weathering cycle through timescales of hundreds of

201 thousands of years [51,53].

202 We show the normalized temporal evolutions of the responses to emissions of selected

203 WMGHGs in Figure 1. These responses, computed for both a pulse emission (Figure 1a,c)

204 and constant sustained emissions (Figure 1b, d), are simulated following the approach used

205 in the $5^{\text {th }}$ IPCC assessment report [1] (see Methods in the Supplementary Information for

206 details). The longer the lifetime of the gas, the higher the emission fraction remaining

207 airborne over time (Figure 1a). Under constant sustained emissions (Figure 1b), the

208 normalized increase in radiative forcing asymptotically tends towards a maximum that is

209 proportional to the product of the atmospheric lifetime of the gas, its radiative efficiency,

210 and the emission rate. The time taken to approach this maximum value is critically

211 dependent on the lifetime, because it determines how soon atmospheric concentrations

212 reach steady state. Short-lived species are near maximum within a few decades, while for

213 others the steady state will not be reached for centuries or millennia. The temperature

214 response to a pulse of short-lived emissions shows a roughly symmetric rise and fall (Figure 
215 1c), because the climate system has insufficient time to fully respond before the perturbation

216 has disappeared [20]. On the other hand, gases with longer lifetimes are persistent enough

217 that the resulting long-term warming is governed by the equilibrium climate sensitivity [54]

218 and some do not dissipate even on millennial time scales $[45,53]$. The result is that the

219 warming from long-lived GHGs remains almost constant or decreases only slowly after the

220 temperature peak or a hypothetical cessation of emissions, and for some gases it is nearly

221 irreversible over many human generations. In the case of $\mathrm{CO}_{2}$, the temperature does not

222 decrease significantly even if emissions cease entirely (Figure 1d). For extremely long-lived

223 gases like $\mathrm{CF}_{4}$, the temperature continues to rise for a century or more following cessation of

224 emissions owing to the multi-century timescales of the ocean/atmosphere adjustments to

225 constant warming $[37,45]$.
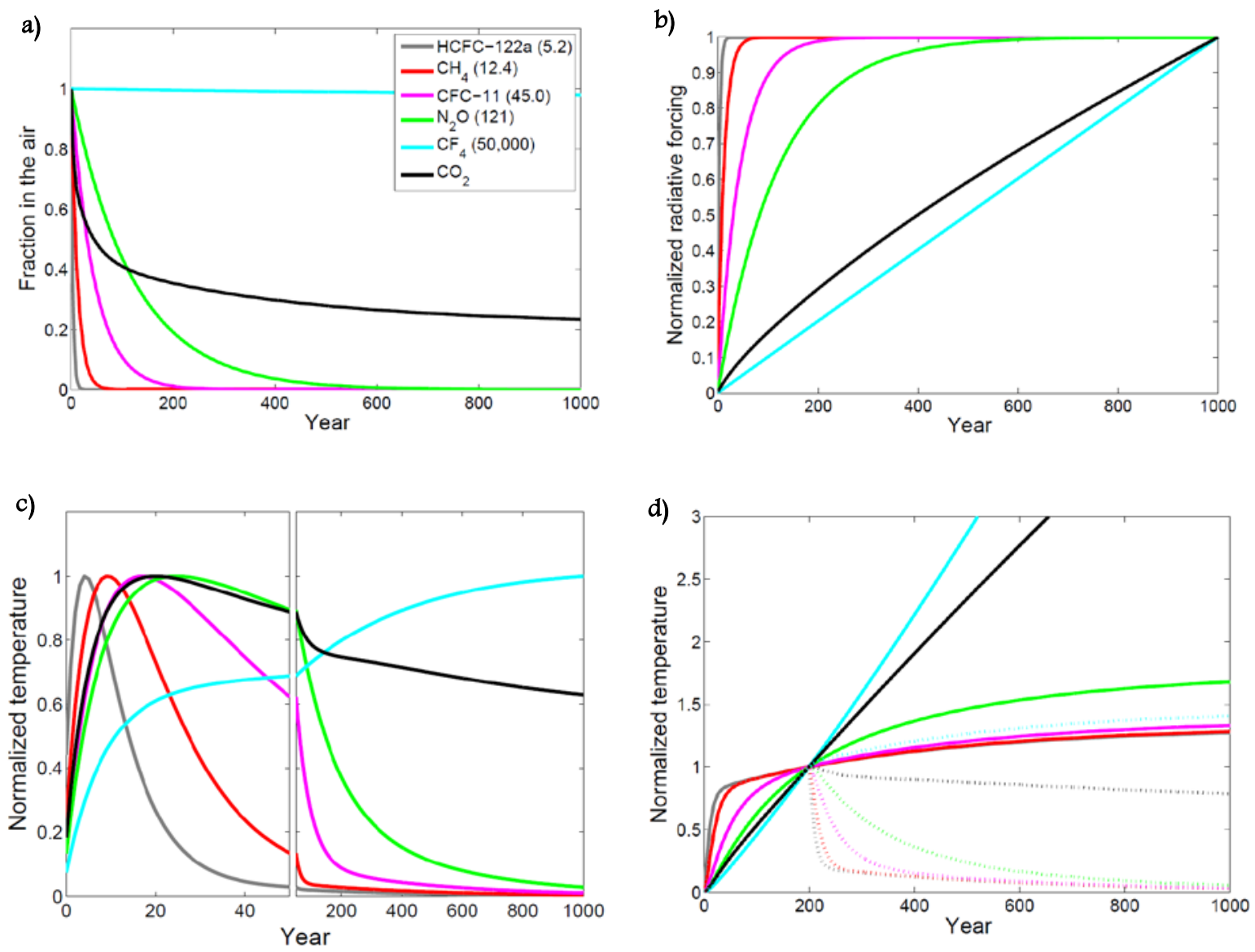
Figure 1 Temporal evolutions of the normalized responses of the climate system to some WMGHGs. a) Fraction

of the gas remaining in the atmosphere following an emission pulse at year zero; b) normalized radiative

forcing under constant emission rates; c) normalized global average surface temperature response to an emission pulse at year zero; d) normalized global average surface temperature response to constant emission rates (dotted lines show the response to a sudden cessation of emissions at year 200). Each curve is normalized to its maximum value in the one thousand year time interval in b) and c). The temperature responses are normalized to the respective value at year 200 in d). The selected gases are those found in IPCC AR5 Table 8.7 [1], with the replacement of HFC-134a (a gas with lifetime similar to methane) with a gas with lifetime of a few years $(\mathrm{HCFC}-122 \mathrm{a})$.

As pointed out in the climate science literature $[20,23,33]$ and reiterated in the last IPCC $5^{\text {th }}$ Assessment Report [1], the aggregation of WMGHGs to $\mathrm{CO}_{2}$-equivalents is challenging because it groups together gases with lifetimes ranging from a few years to several thousands of years. Mitigation of either short-lived species or $\mathrm{CO}_{2}$ achieves different goals that are not equivalent in terms of climate system responses. For mitigation actions taking

241 place today, or several decades before a targeted temperature peak, metrics like GWP100 overestimate the importance of short-lived gases but underestimate their impact on nearterm change $[18,20,33]$. For example, $\mathrm{HCFC}-122 \mathrm{a}$ and $\mathrm{N}_{2} \mathrm{O}$ have very different lifetimes (5

244 and 122 years, respectively) and temperature impact profiles. The temperature change from $245 \mathrm{~N}_{2} \mathrm{O}$ is approximately 6.5 times larger than that from HCFC-122a 100 years after a pulse 246 emission, whereas the temperature change from HCFC-122a is about 1.5 times higher than 247 that from $\mathrm{N}_{2} \mathrm{O}$ after 20 years from a pulse emission. Despite these differences, they are 248 considered as almost equal when converted to $\mathrm{CO}_{2}$-equivalents because they have relatively 249 similar GWP100 values, 265 for $\mathrm{N}_{2} \mathrm{O}$ and 258 for HCFC-122a [1]. This example underlines 250 the extent to which the choice of a metric can skew the apparent importance of different 251 gases, and why the use of a diverse array of metrics is desirable for matching specific policy 
goals. The simple replacing of GWP100 with an alternative metric would not mitigate these concerns because any choice that works for one dimension of the climate system, e.g. shortterm impacts, inevitably risks overlooking others, e.g. long-term impacts.

\section{Emissions and temperature peaks}

There is a growing interest in the climate science community to infer simplified metrics and climate policy frameworks from the relationships between temperature peaks and emissions [40, 55-57]. In Figure 2, we show the temperature peak dynamics of different WMGHGs following four idealized emission trajectories. These trajectories, modelled with a triangular temporal distribution (Figure 2a), have either the same cumulative emissions and different maximum emission rates (E1 and E2), or the same maximum emission rate and different total emissions (E3 and E4). When the temperature responses to E1 and E2 are compared (Figure $2 b$ ), gases with short lifetimes have different temperature peak values (e.g., up to 40\% lower under E2 than E1 for HCFC-122a), whereas nearly identical maximum temperatures are achieved by gases with longer lifetimes. Under constant cumulative emissions, temperature changes from gases with short lifetimes are sensitive to the maximum rate at which emissions occur, and the sensitivity gradually decreases while the lifetime of the gas increases. Temperature changes from gases with longer lifetimes become more sensitive than short-lived species to specific emission trajectories if total cumulative emissions differ (Figure 2c). For instance, the temperature peak reached by $\mathrm{CO}_{2}$ emissions is about 30\% lower under E4 than E3. We compare the effect of emission rates and cumulative emissions on the temperature responses in Figure $2 d$, where the normalized temperature peak differences are plotted against the lifetime of the gases. Gases in the top right corner $\left(\mathrm{CO}_{2}\right.$ and $\left.\mathrm{CF}_{4}\right)$ have higher sensitivity to cumulative emissions, whereas if a gas lies in the 
top left corner (HCFC122a) has a strong sensitivity to emission rates. The temperature

277 increase from short-lived emissions thus primarily depends on today emissions, which

278 mainly affect the rate and magnitude of climate change over the next few decades [37, 38,

$27940,58,59]$. On the other hand, the temperature impact from long-lived gases like $\mathrm{CO}_{2}$ and

$280 \mathrm{CF}_{4}$ gradually accumulates over time and, rather than with the rate and timing of emissions,

281 it scales with the cumulative amount of emissions, including those occurred in the past [40,

$28253,55,60,61]$.

a)

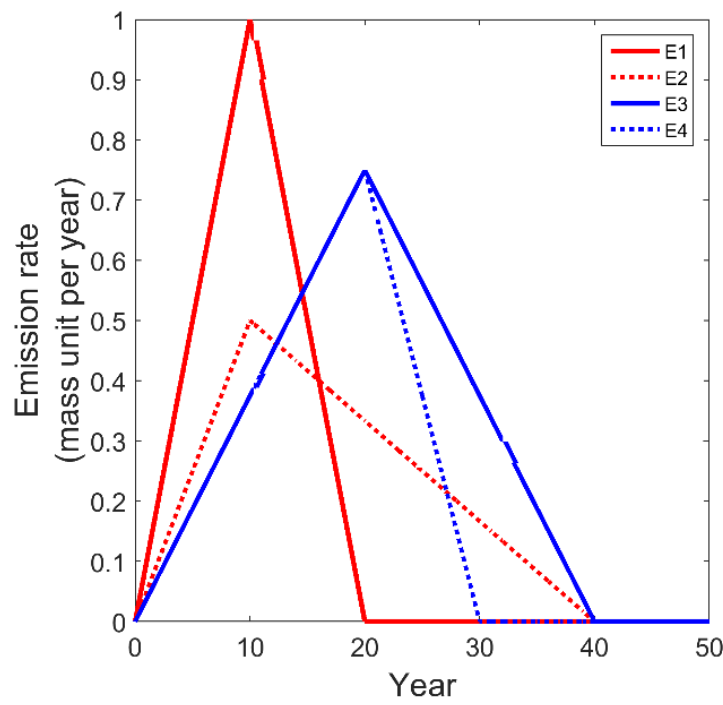

c)

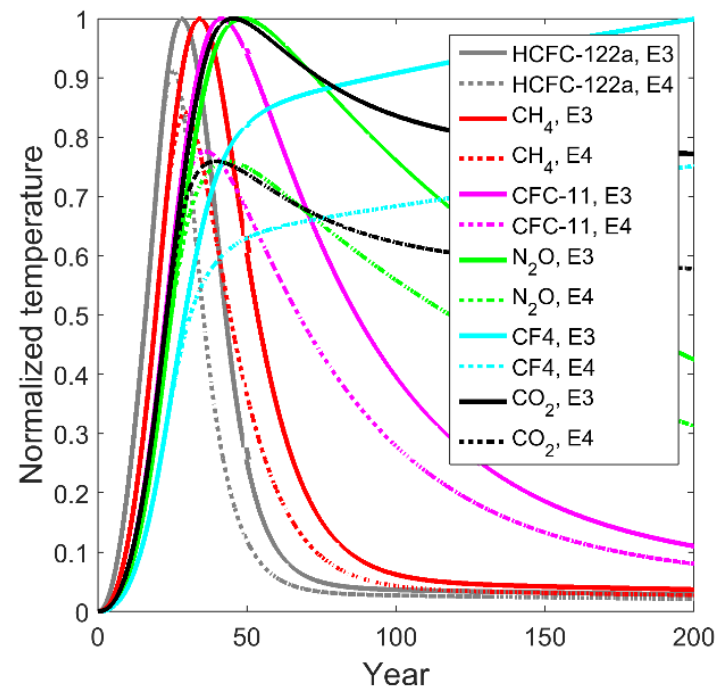

b)

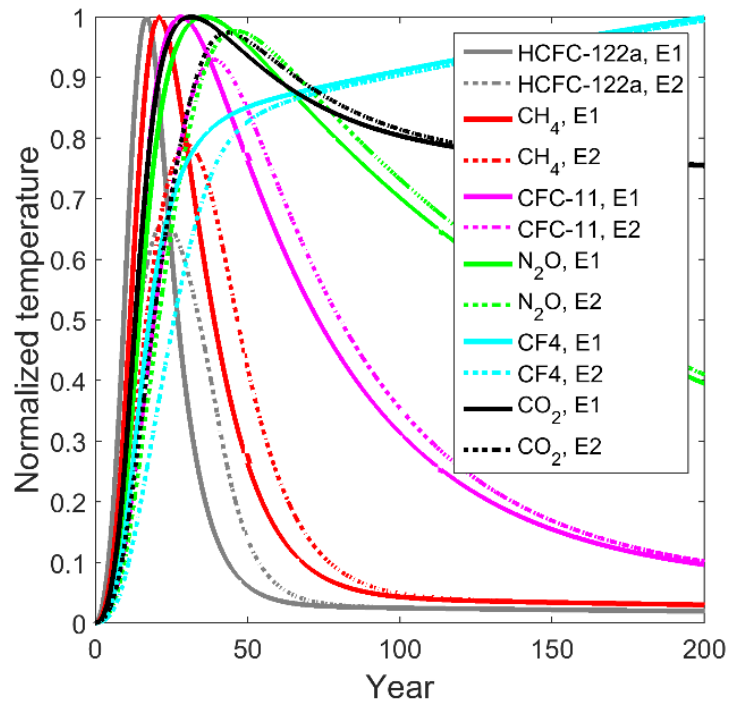

d)

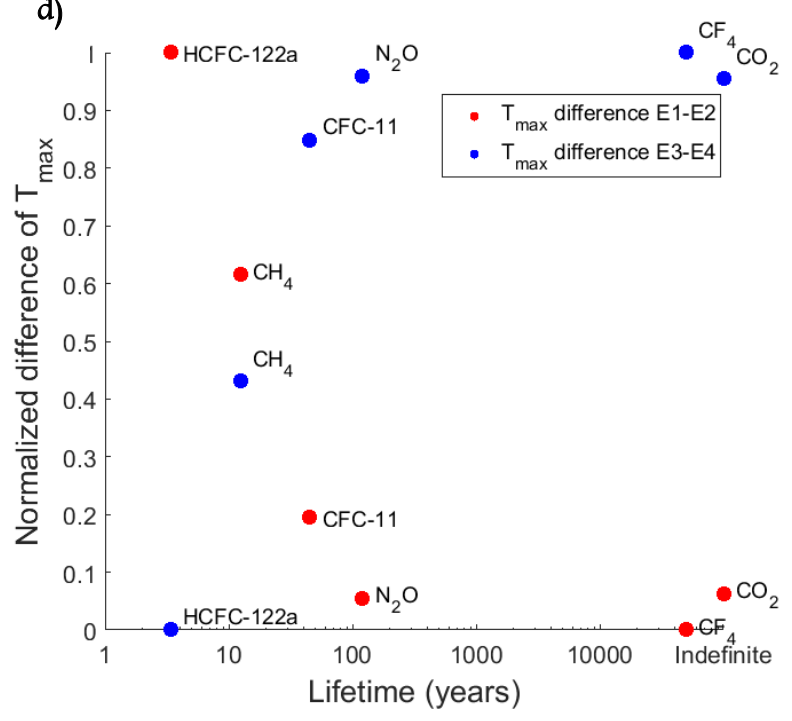


Figure 2: Sensitivity of the temperature response of WMGHGs to emission rates. a) idealized emission rates peaking and declining. E1 and E2 have the same amount of cumulative emissions but different maximum emission rates (E1 > E2); E3 and E4 have the same maximum emission rate but different cumulative emissions (E3 > E4); b) normalized temperature responses to E1 and E2; c) normalized temperature responses to E3 and E4; d) normalized difference of the temperature peak $\left(T_{\max }\right)$, computed from the responses in $\left.b\right)$ and c), for each WMGHG as a function of the lifetime of the gas (logarithmic scale). The red dots indicate the normalized differences in the temperature peak values of each WMGHG to emission scenarios E1 and E2 (Figure 2b). The blue dots are for the normalized differences in $\mathrm{T}_{\max }$ under emission scenarios $\mathrm{E} 3$ and $\mathrm{E} 4$ (Figure 2c). Values close to 1 indicate high sensitivity of $\mathrm{T}_{\max }$ to emission rates (red dots) or cumulative emissions (blue dots). The profile for each gas in b) and c) is normalized to the respective maximum value from the emission scenario E1 and E3, respectively. For $\mathrm{CF}_{4}$, the temperature at 200 years is taken as the normalizing factor.

The relationship between emissions and temperature peaks is used to produce simplified emission metrics and approaches $[37,40,55,56]$. If climate policy is focused on avoiding a specific temperature threshold, its achievement largely depends on the cumulative emissions of long-lived gases until the year of the peak, and on emission rates of short-lived species in the one or two decades preceding the peak $[40,62,63]$. In such a context, emissions of short-lived gases should be progressively more weighted as the temperature peak is approached, and less if it is more distant. There are options to link metric values to the gradual approaching of climate targets, such as time dependent formulations of GWP or GTP $[18,28,33]$ and other metrics explicitly connected to a climatic threshold [14, 34]. Another option that is gathering increasing interest is the "transient climate response to cumulative carbon emissions" (TCRE) [60], which is formally defined as the warming due to 306 one trillion ton of cumulative carbon emissions and is based on the linearity between temperature peak and cumulative emissions [55, 61]. Earlier estimates of the TCRE suggested an average value of $1.6 \pm 0.5^{\circ} \mathrm{C}$ per Tera ton carbon (TtonC) emitted [61], while 
per TtonC [60]. Although so far mainly validated for $\mathrm{CO}_{2}$, the concept of TCRE can also be

311 extended to other long-lived GHGs [44]. Similarly, the temperature contribution from short-

312 lived gases can be approximated using scaling factors applied to the maximum emission

313 rates $[37,40,58,59]$. The use of metrics based on temperature peak dependencies on either

314 emission rates or cumulative amounts within an LCA framework has not been explored yet.

315 On one hand, this approach would allow a multi-basket framework where the various

316 forcing agents are grouped together on the basis of their lifetimes, thus avoiding the practice

317 to group together species with very different lifetimes. On the other hand, different sets of

318 emission metrics would still be needed to aggregate emissions to common units, and the

319 selection of the metrics to be used in the different baskets would still remain based on value-

320 laden choices, as it would be dependent on the preferred policy goal [41]. Still open is also

321 the question on how to weight one basket with respect to the other, with some arguing that

322 any trading between the different baskets should not be allowed $[37,38]$.

\section{Near-term climate forcers (NTCFs)}

325 In addition to emissions of WMGHGs, human activities perturb the climate system through

326 emissions of pollutants such as nitrogen oxides $\left(\mathrm{NO}_{\mathrm{x}}\right)$, carbon monoxide $(\mathrm{CO})$, volatile

327 organic compounds (VOCs), black carbon (BC), organic carbon (OC), sulphur oxides (SO ${ }_{x}$ ),

328 and ammonia $\left(\mathrm{NH}_{3}\right)$. Some of these pollutants are precursors to the formation of

329 tropospheric ozone $\left(\mathrm{NO}_{\mathrm{x}}, \mathrm{CO}, \mathrm{VOCs}\right)$, others are primary aerosols $(\mathrm{BC}, \mathrm{OC})$ or precursors to

330 secondary aerosols $\left(\mathrm{NO}_{\mathrm{x}}, \mathrm{SO}_{\mathrm{x}}, \mathrm{NH}_{3}\right)$. These species have lifetimes shorter than the

331 hemispheric mixing time and are usually called near-term climate forcers (NTCFs). The

332 atmospheric concentrations of NTCFs are very heterogeneous, with high concentrations

333 around the emission source, and therefore the resulting impact largely depends on the 
source region [64-67]. Although short-lived GHGs like $\mathrm{CH}_{4}$ are sometimes referred to as

335 NTCFs, we here restrict this definition to species with inhomogeneous atmospheric

336 concentrations that are not well-mixed.

337 The considerations above associated with the characteristics of the temperature response to

338 short-lived species also apply to NTCFs. Emissions of NTCFs may also have an effect on

339 precipitation patterns through changes in cloud formation processes and cover [2], which

340 have recently been quantified in terms of emission metrics [31]. In general, the confidence

341 level in the predicted climate impacts from NTCFs is lower than that for WMGHGs,

342 especially in the cases in which aerosol-cloud interactions are important (see section 8.5.1

343 in ref. [1] and the latest specific IPCC chapter on the matter [2]). These emissions are

344 coupled to the hydrological cycle and atmospheric chemistry and involve highly complex

345 processes that are challenging to validate. The net climate impacts of NTCFs are the result of

346 many opposing effects with different temporal evolutions at play. $\mathrm{NO}_{\mathrm{x}}$ species are very

347 reactive and affect climate through many nonlinear chemical interactions with various

348 timescales $[21,46]$, including nitrate and ozone formation, changes in $\mathrm{CH}_{4}$ concentration

349 and thereafter stratospheric water vapour $[46,50] . \mathrm{NO}_{\mathrm{x}}$ also influences $\mathrm{CO}_{2}$ and the global

350 carbon cycle through the fertilization effect of nitrogen depositions. Other ozone precursors

351 are CO and VOCs, which increase the concentration of ozone on short time scales and by

352 affecting the levels of hydroxyl $(\mathrm{OH})$ radical, and thereby of $\mathrm{CH}_{4}$, they also initiate a net

353 positive long-term ozone effect $[3,65]$. Aerosol species influence the climate mainly through

354 absorption (BC) or scattering (OC, sulphate and nitrate) of solar radiation and other indirect

355 effects, like deposition of BC on snow. Aerosols are either directly emitted from sources

356 (primary aerosols, like BC and OC), or they are formed in the atmosphere via several

357 processes (secondary aerosols, like sulphate after oxidation of $\mathrm{SO}_{2}$, and $\mathrm{OC}$ from

358 condensation of organic compounds). 
a)

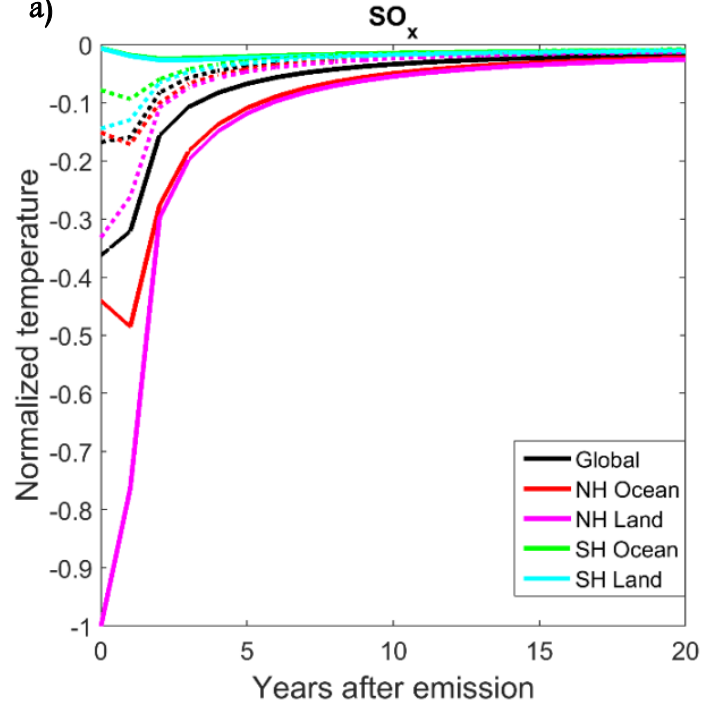

c)

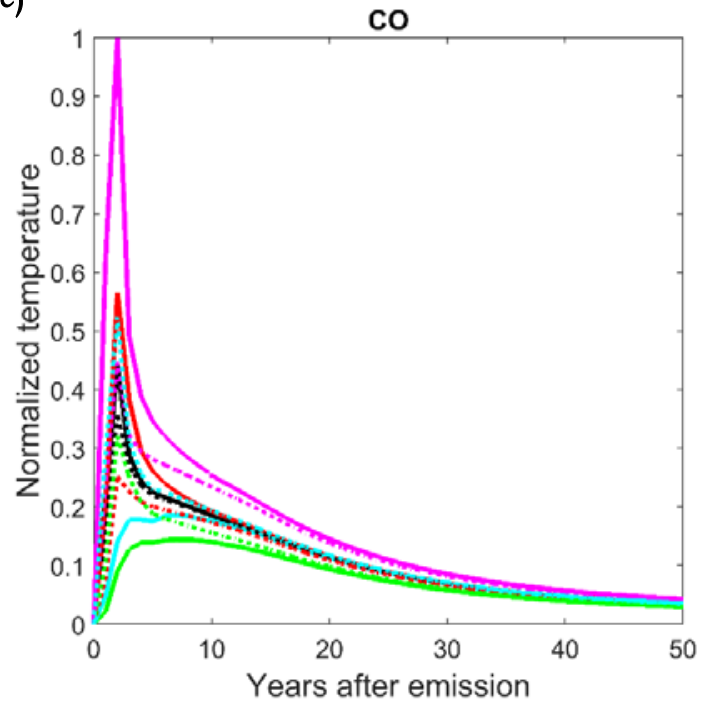

b)

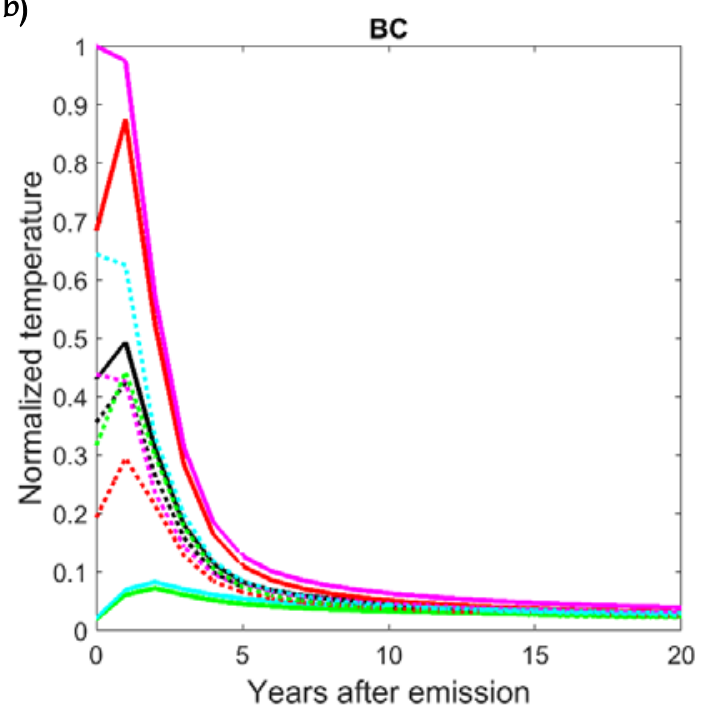

d)

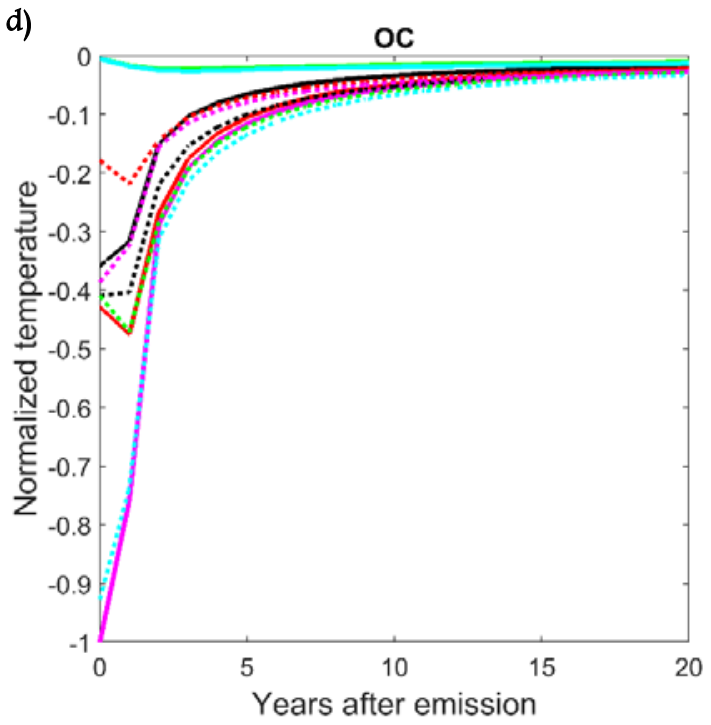

359 Figure 3 Global and regional normalized temperature responses to pulse emissions of selected NTCFs ( $\mathrm{SO}_{\mathrm{x}}, \mathrm{BC}$,

360 CO and OC) located in the northern or southern hemisphere. The responses to emissions in the northern

361 hemisphere (NH) are shown with solid lines, those to emissions from the southern hemisphere (SH) with

362 dashed lines. The temperature response is averaged globally and over the land and oceans of NH and SH. For

363 each specie, curves are normalized to the maximum (for $\mathrm{BC}$ and $\mathrm{CO}$ ) or minimum (for $\mathrm{SO}_{\mathrm{x}}$ and $\mathrm{OC}$ ) value of

364 all the responses.

Figure 3 shows the normalized temperature effects from pulse emissions of three aerosol

367 species $\left(\mathrm{SO}_{\mathrm{x}}, \mathrm{BC}\right.$ and $\left.\mathrm{OC}\right)$ and one ozone precursor (CO). Emissions are located in the 
northern or southern hemisphere, and the temperature response is averaged both globally and over macro regions like the land and oceans of the northern and southern hemispheres. The responses, which merely have illustrative purposes, are computed using the simplified climate model MAGICC6 [68], a model widely used in the climate science community (see Methods in the Supplementary Information). Emissions from different regions have different lifetimes and the responses are regionally dependent. The global averaged temperature has significant variations with respect to the regional trends. The climate impact response to an emission pulse is generally higher in the northern hemisphere, where there is the strongest sensitivity to forcing, and over the land than the oceans, due to differences on evaporation [69]. Emissions of $\mathrm{BC}$ have the largest impact on regional average temperature change when located in the northern hemisphere, because BC can be easily transported to the white surfaces of the arctic and thereby decrease albedo. The response to CO and VOCs are less heterogeneous because they have longer lifetimes (from one to three months) and are approximately well-mixed on a hemispheric spatial scale. As discussed elsewhere [20, 66, 70], they are less dependent on emission location and model configurations, although the consideration of vegetation effects of ozone and aerosol responses can increase variability [48].

Climate impacts from NTCFs are currently excluded from LCA studies, carbon footprints, or international global climate agreements. Their possible inclusion has been debated $[3,5,65$, $70,71]$ and, in some cases, explicitly argued $[3,5,71]$. However, the characterization of NTCFs to $\mathrm{CO}_{2}$ equivalents is even more difficult than it is for short-lived gases because of the very short lifetime of the forcing, its spatial heterogeneity, and the larger uncertainty. Global metrics like GWP normally use globally-averaged inputs to produce globallyaveraged measures and give no information about the spatial variability of the impact. Global metrics available in the literature for NTCF emissions located in different regions are 
393 presented and discussed in the $5^{\text {th }}$ IPCC assessment report [1]. There is not a robust

394 relationship between the region of the emission and the metric value [20], and the inter-

395 model variability is sometimes larger than the variability between emission regions [50, 72].

396 Measures that rely on global averages or long integration times do not fully represent the

397 temporal and spatial characteristics of the responses $[73,74]$. The application of a metric

398 that is first calculated locally and then averaged globally could be one way of capturing a

399 more complete and informative signal than one that uses global mean outputs [73].

400 Regional specific responses and emission metrics for NTCFs are also available [50, 64, 74,

401 75]. Absolute Regional Temperature Potentials (ARTP) are computed using fully coupled

402 atmosphere-ocean climate models and approximate the time-dependent temperature

403 response at four latitude bands as a function of the regional forcing imposed by various

404 climate pollutants in all bands [75]. These metrics allow the assessment of the climate effects

405 from NTCFs with some regional resolution without coupling the analysis with sophisticated

406 climate models. However, additional studies are required to determine the robustness of

407 ARTPs and explore their feasibility for life cycle impact assessment methods. Existing climate

408 impact frameworks rely on the assumption that the emission location does not affect the

409 response of the climate system and the climate change impact category has a global scale.

410 These assumptions hold for WMGHGs but not for all NTCFs. Species like $\mathrm{NO}_{\mathrm{x}}, \mathrm{SO}, \mathrm{BC}$ and

411 OC would ideally require the formulation of sub-global emission locations and impact

412 categories for using the corresponding regional metrics.

413 There are other important caveats associated with the accounting of the climate impacts

414 from NTCFs. As they can have significant contributions to global warming, their inclusion in

415 LCA can make their mitigation an attractive proposition to achieve multiple environmental

416 goals at the same time [76], because these species have adverse effects in other

417 environmental impact categories than climate change, like human and ecosystem health . 
On the other hand, some NTCFs have cooling effects, and their accounting may result in a

419 partial offsetting of the warming effect of the total aggregated emissions. This would result

420 in the attribution of climate benefits to species which are responsible of air pollution and

421 damage to ecosystems. LCA methodology includes many environmental impact categories

422 and is by definition well suited to inform about the possible shifts of impacts across

423 categories. However, risks of this type are higher in carbon footprint studies or other

424 applications where the goal is limited to the assessment of climate change impacts only.

425 Accounting for NTCFs using metrics like the GWP100 would bring to common unit species

426 with very different climate impact profiles and expand the abatement options available.

427 Decision-makers could for instance prioritize mitigation of NTCFs and delay reductions in

428 long-lived species like $\mathrm{CO}_{2}$, thereby causing irreversible long-term warming for the sake of

429 reducing near-term rate of warming. Another important aspect is the consideration that

430 NTCFs are frequently co-emitted, and this has implications for the benefits that can be

431 achieved by their mitigation [62, 63]. For instance, with approximately $0.64 \mathrm{~W} \mathrm{~m}^{-2}, \mathrm{BC}$ is

432 the third largest radiative forcing component for the period $1750-2011$ after $\mathrm{CO}_{2}$ and $\mathrm{CH}_{4}$

433 [1]. One can therefore argue that a reduction in BC emissions will bring considerable

434 benefits for the climate. However, the benefits from a decrease in BC emissions are

435 dampened by the simultaneous reduction of emissions of species like $\mathrm{SO}_{\mathrm{x}}$ and $\mathrm{OC}$, which

436 have cooling contributions $[62,63]$.

\section{6. Land use and land cover change (LULCC)}

439 Climate impacts from a change in land use or management are frequently associated to

440 emission or removal of WMGHGs like $\mathrm{CO}_{2}, \mathrm{~N}_{2} \mathrm{O}$ and $\mathrm{CH}_{4}$. Direct GHG emissions from land

441 use changes such as deforestation or afforestation, as well as those from changes in above- 
ground or soil carbon content after a change in management, are usually accounted for in

443 LCA, when data are available $[4,77]$. The consideration of possible emissions associated with

444 indirect land use changes via market-mediated effects, that is the change in land use in one

445 place caused by a change in production in another place, is widely debated [78, 79]. Land

446 use without land-cover change (e.g., managed or harvested forests) have traditionally been

447 treated under a default carbon neutrality assumption [80], thus ignoring the temporal

448 asymmetry between $\mathrm{CO}_{2}$ emission and uptake fluxes, which can be rather significant for

449 forests. Recent studies show how the climate forcing impact from this asymmetry can be

450 assessed through site-specific emission metrics that embed post-disturbance carbon

451 dynamics [81]. Emission metrics or temporally differentiated emission inventories are also

452 used to compute the climate change implications of anthropogenic carbon sequestration and

453 storage in products $[11,82-84]$.

454 Relatively more challenging and less common is the quantification of the biogeophysical

455 effects following a change in land use or land cover. Modifications of the surface energy

456 balance through changes in surface albedo, evapotranspiration (the fluxes of heat and water

457 between the vegetation and the atmosphere), and surface roughness (the aerodynamics of

458 the vegetation cover), can have implications for the local [85-87] and global [88-90]

459 climate, either directly or indirectly $[89,91]$. The global temperature impact from these

460 effects can be of the same order of magnitude as the impact associated with $\mathrm{CO}_{2}$ emission or

461 removal fluxes $[88,90,92,93]$, whether or not the land cover change is long lasting, such

462 as in afforestation or deforestation [90, 94], or transient, such as in forest management or

463 post-fire forest recovery $[7,95]$. Nevertheless, accounting for changes in albedo and other

464 biogeophysical properties is not currently required in the formal rules for quantifying the

465 climate effects of land use activities [96]. This is despite the large evidence from climate

466 simulation studies [88, 90, 96-98] or empirical observations [86, 99], where the importance 
to go beyond a simple carbon accounting framework when assessing the impacts of LULCC activities on climate is frequently highlighted [7, 92, 96-98]. It has been explicitly argued that "ignoring biophysical interactions could result in millions of dollars being invested in some mitigation projects that provide little climate benefit or, worse, are counter-

471 productive" [96].

Biogeophysical properties vary with surface cover and have high spatial and seasonal

variations. There are differences between summer and winter, especially in areas affected by seasonal snow cover. For instance, forests usually have lower albedo than open lands such as grassland or cropland, especially during snow covered periods. Biogeochemical effects following a change in forest cover usually dominate at low latitudes, while biogeophysical contributions are stronger at high latitudes [88-90, 100]. Biogeophysical effects are significant also when changes in management occur on the same land use type, such as irrigation, crop rotation, and forestry $[7,98,99]$. In general, climate impacts vary in spatial scale and depend on complex, and often nonlinear, mechanisms. Compared to grass, trees are generally more efficient in transferring water from the soil to the atmosphere because of

482 their deeper roots and larger leaf area, and forests thus tend to maintain a cooler local surface temperature by releasing more energy in the form of latent heat than sensible heat. Hence, conversion from forest to grassland tends to warm the local surface, and it also tends to reduce the roughness of the landscape and thus to reduce the turbulence in the boundary layer. However, it is difficult to predict the effect that this reduction may have on surface temperature, because the reduction of heat and water vapour transport associated with 488 reduced turbulence may be compensated by greater gradients of humidity and temperature 489 between the surface and the atmosphere $[89,96]$.

490 Biogeophysical effects differ in nature. Changes in surface albedo and emissivity modifies 491 global temperature by directly altering the Earth's radiative balance, while changes in 
evapotranspiration and surface aerodynamics do not imply any direct perturbation to the earth's radiative balance [89]. The quantification of the climate change effects from evapotranspiration and surface roughness is complex. The attribution of regional and global climate change effects to these forcing agents is highly uncertain and limited in evidence, owing to a wide spread in model estimates and differences between observations and model results $[87,91,101]$. Modelling changes in evapotranspiration and surface roughness also requires knowledge of numerous vegetation structural, physiological, and environmental parameters [97, 101], posing formidable challenges for the accounting of these effects in climate impact assessment studies. On the other hand, changes in surface albedo are rather more certain and less challenging to quantify. The $5^{\text {th }}$ IPCC assessment report classified the radiative forcing estimates from surface albedo changes with a high confidence level, as it has robust evidence with well documented high precision measurements [1]. Surface albedo is also the most important biogeophysical mechanism influencing the global climate in extra-tropical regions, especially in areas experiencing seasonal snow cover $[88,90,98]$. Because they can be measured in terms of radiative forcing, impacts from changes in surface albedo are frequently converted to $\mathrm{CO}_{2}$ equivalents using either carbon equivalent factors [97, 102] or more conventional emission metrics like GWP or GTP [13]. However, because of the non-linear and high spatial heterogeneity of the climate forcings from landatmosphere perturbations as well as the different temporal behaviour, the development and possible routine applications of climate metrics for LULCC in LCA need to be land coverand location-specific. Like for NTCFs, radiative forcing from albedo changes located in different regions affect climate heterogeneously [89, 90], with radiative forcings at high latitudes being more effective in changing global temperature than radiative forcing at low latitudes [103]. Because changes in land surface aerodynamic and physiological properties often dampen the radiative temperature change at the local surface [89], global radiative 
forcings from WMGHGs, like $\mathrm{CO}_{2}$, and LULCC do not produce the same global mean

518 temperature response when added together, and more accurate estimates are achieved when

519 the individual climate responses are used [104]. However, the lack of regional temperature

520 response functions and metrics for radiative forcings originated from changes in

521 biogeophysical effects at various locations has so far limited the possibilities to perform

522 temperature-based analyses without coupling the study with global climate models.

523 In addition to WMGHGs and surface albedo, changes in land cover have a third direct effect

524 on the global radiation balance by altering emissions of biogenic VOCs (BVOCs), which

525 rapidly oxidize in the atmosphere generating multiple warming and cooling climate

526 pollutants like ozone and biogenic secondary organic aerosols [3, 105]. The photochemical

527 processing of BVOC emissions influences the oxidation capacity of the atmosphere, which

528 affects the lifetime of $\mathrm{CH}_{4}$ and the production of other secondary aerosols (sulphate and

529 nitrates). Even if BVOC emissions are formally quantified as a terrestrial biogeochemical

530 feedback that responds to anthropogenic climate change [52], we briefly discuss them here

531 given the strict link they have with LULCC. As for the other NTCFs, the net radiative patterns

532 are highly spatially inhomogeneous. The net radiative forcing from historical BVOC

533 emission reductions from expansion of agricultural areas is estimated in a negative (cooling)

534 contribution [3]. Conversely, increasing BVOC emissions following LULCC involving

535 reforestation or afforestation strategies cause a positive radiative forcing [71]. Despite

536 relevant recent progress, important uncertainties still persist. Current generation models

537 underestimate the amount of organic aerosols in the atmosphere and are unable to fully

538 reproduce the variability found in the measurements [1]. As NTCFs, BVOC oxidation

539 products are also important for the growth of newly formed particles up to cloud

540 condensation, so they indirectly influence climate through changes in cloud albedo [106].

541 These atmospheric aerosol processes changing cloud droplet concentrations and radiative 
542 properties are among the least understood in climate research, and their contributions to the

543 global radiation budget are considered as one of the largest source of uncertainty in the

544 estimation of radiative forcing over the industrial period [106]. Results are not consistent

545 across models, with estimates ranging between $+0.23 \mathrm{~W} \mathrm{~m}^{-2}$ and $-0.77 \mathrm{~W} \mathrm{~m}^{-2}$ [3]. All these

546 aspects make a possible consideration of the contributions from aerosol-cloud effects in LCA

547 and similar studies unrealistic for the short and medium term.

\section{The way forward}

550 Anthropogenic global warming is caused by a variety of forcing agents with different

551 physical properties and lifetimes ranging from few days, like black carbon, to several

552 thousands of years, like $\mathrm{CF}_{4}$. Climate impact methods used in LCA are challenged when it

553 comes to dealing with aspects like the various timescales of the responses to different GHGs,

554 impacts from NTCFs and LULCC, and their temporal and spatial variability. Emissions can

555 also be aggregated by metrics other than GWP100. Alternative metrics would allow the

556 representation of different dimensions of climate change impacts, but would not sidestep the

557 value-laden considerations of the relative weighting. Value judgements are embedded in

558 metric formulations, most notably through the choice of time horizon, of climate impact

559 parameters, and by whether the indicator refers to a time-integrated or instantaneous

560 quantity. Any preference of one metric over another arguably favours the representation of

561 some aspects of the climate system response and at the same time discount others.

562 There are considerable uncertainties in the attribution of climate impacts to specific forcing

563 agents. Scientific uncertainties are larger for temperature-based metrics than for those

564 based on radiative forcing, and for NTCFs, BVOCs, or non-radiative LULCC mechanisms

565 than for WMGHGs or changes in surface albedo following LULCC. The presence of 
uncertainties should not per se be an overriding constraint for using metrics and modelling impacts [20]. If the main policy goal is to keep global temperature below a certain threshold, the uncertainties and timing of political choices (i.e. a delay in action) are often those with the largest cost-risk distributions, and may actually swamp the uncertainties associated with the parameterization of the climate system [107].

Concerning the aggregation to common units, it is impossible to identify a single metric that can produce a balanced representation of the overall climate impact from such a diversity of forcing agents. Different climate policy goals may lead to different conclusions about what is the most suitable metric to assess that policy. For instance, the use of GWP100 in LCA has the inadvertent consequence of assessing emissions for their contributions to global temperature over a timeframe of about four decades $[35,36]$, with no direct connections to peak warming. GWP100 only becomes an indication of the contributions to peak warming under the arguably optimistic assumption that global $\mathrm{CO}_{2}$ emissions will approach zero within about 40 years, so that the global temperature will approach stabilization. The characterization of different emissions to $\mathrm{CO}_{2}$-equivalents implicitly suggests that one can freely choose which emissions to reduce in order to achieve the same improvement in the climate system performance of a product. However, the same net reduction of the total aggregated emissions in $\mathrm{CO}_{2}$-equivalents will have different climate effects at different times, depending on whether it is obtained through a reduction in long-lived or short-lived species. If emissions of long-lived gases continue to rise, the mitigation of short-lived species would temporarily reduce the rate of warming but cannot avoid the risk of passing warming thresholds, because as long as the concentration of $\mathrm{CO}_{2}$ is allowed to keep growing, the reaching of those thresholds is only temporally postponed. Any delay in mitigation of $\mathrm{CO}_{2}$ emissions will lead to nearly irreversible warming. Within the global policy goal of limiting warming to $2^{\circ} \mathrm{C}$ above pre-industrial levels, mitigation of $\mathrm{CO}_{2}$ 
emissions is thus identified as a non-negotiable objective in strategies aiming at constraining

593 lived emissions progressively closes the door for achieving ambitious peak temperature

594 targets.

595 Bridging life cycle impact assessment methods with climate science is essential to provide 596 decision makers with more robust climate change impact studies that acknowledge the variety of forcing agents at play and the caveats of their aggregation. There are metrics other than GWP100 and climate forcing agents other than WMGHGs. Explicit consideration of alternative metrics by LCA practitioners would allow the characterization of climate change impacts over multiple timescales and with regard to diverse and contrasting policy goals.

601 For instance, the use of metrics like GWP20 or GWP100 can provide information about the 602 time-integrated contributions to global warming in a short/medium term, whereas GTP100 603 provides information about the instantaneous contributions to global warming on a longer 604 timeframe. If GWP aligns well with the LCA ambition to prefer integrated impacts, GTP 605 provides the possibility to explicitly link global warming contributions to a climate target, 606 based on planetary boundary and/or policy considerations. In general, the utilization of 607 multiple metrics provides complementary information on the implications of mitigating 608 gases with varying lifetimes, and shows the extent to which results are sensitive to the 609 choice of metric or robust across a range of choices. The inclusion in existing LCA databases 610 and impact assessment methods of the spectrum of the metrics available in the latest IPCC 611 assessment report will facilitate their application by LCA practitioners.

612 The consideration of NTCFs in LCA presents challenges at an inventory and characterization 613 level. Most of the NTCFs are already tracked by the majority of the life-cycle inventory 614 databases, as they contribute to other environmental impact categories, except for BC and 615 OC emissions. Although they can be indirectly quantified from emissions of particulate 
616

617 Characterization of their impacts on climate should consider the higher level of

618 uncertainties associated with metrics for NTCFs, and ideally consider the range of possible

619 metric values summarized in the latest IPCC report. The LCA community should closely

620 follow updates on quantification of impacts from NTCFs as the climate science community is

621 continuously improving the robustness of characterization factors for NTCFs.

622 Regional climate change categories can also be formulated in the future when robust

623 estimates of metric values for regional responses to NTCFs become available. Inventory

624 databases should already be adapted by elaborating spatial-explicit emission inventories

625 that keep track of emission regions.

626 The time is ripe for the LCA community to consider the complexity of climate science and

627 gain insights on the implications associated with the selection of emission metrics for the

628 intended goal of the analysis. Rather than using a single default metric for WMGHGs in all

629 applications, analysts should acknowledge the various forcing agents and the caveats

630 associated with the aggregation of species with different lifetimes to common units. The

631 sensitivity of the results to the type of metric used should be explored. When a choice is to

632 be made, this can be done consistently with the aspects of climate change that are most

633 relevant for the particular application. In any case, it is important to be aware and

634 transparent about the choice of metric, its meaning, and the inherent value judgments it

635 entails when interpreting and communicating results. A continuous bridge between the two

636 communities is desirable in the future to keep LCA methods up-to-date with the latest

637 developments in climate science, and simultaneously engage climate scientists to shape

638 emission metrics and approaches to fit environmental impact assessment frameworks. 


\section{References}

1. Myhre, G., et al., Anthropogenic and Natural Radiative Forcing, in Climate Change 2013. The Physical Science Basis. Contribution of Working Group I to the Fifth Assessment Report of the Intergovernmental Panel on Climate Change T.F. Stocker, et al., Editors. 2013, Cambridge University Press: Cambridge, United Kingdom and New York, NY, USA.

2. Boucher, O., et al., Clouds and Aerosols, in Climate Change 2013: The Physical Science Basis. Contribution of Working Group I to the Fifth Assessment Report of the Intergovernmental Panel on Climate Change T.F. Stocker, et al., Editors. 2013, Cambridge University Press: Cambridge, United Kingdom and New York, NY, USA.

3. Unger, N., Human land-use-driven reduction of forest volatiles cools global climate. Nature Clim. Change, 2014. advance online publication.

4. Hellweg, S. and L. Milà i Canals, Emerging approaches, challenges and opportunities in life cycle assessment. Science, 2014. 344(6188): p. 1109-1113.

5. Peters, G.P., et al., Alternative "Global Warming" Metrics in Life Cycle Assessment: A Case Study with Existing Transportation Data. Environmental Science \& Technology, 2011. 45(20): p. 8633-8641.

6. Tsao, C.C., et al., Increased estimates of air-pollution emissions from Brazilian sugarcane ethanol. Nature Clim. Change, 2012. 2(1): p. 53-57.

7. Cherubini, F., R.M. Bright, and A.H. Strømman, Site-specific global warming potentials of biogenic CO 2 for bioenergy: contributions from carbon fluxes and albedo dynamics. Environmental Research Letters, 2012. 7(4): p. 045902.

8. Caiazzo, F., et al., Quantifying the climate impacts of albedo changes due to biofuel production: a comparison with biogeochemical effects. Environmental Research Letters, 2014. 9(2): p. 024015.

9. Levasseur, A., et al., Considering Time in LCA. Dynamic LCA and Its Application to Global Warming Impact Assessments. Environmental Science \& Technology, 2010. 44(8): p. 3169-3174.

10. Lund, M.T., T.K. Berntsen, and J.S. Fuglestvedt, Climate Impacts of Short-Lived Climate Forcers versus CO2 from Biodiesel: A Case of the EU on-Road Sector. Environmental Science \& Technology, 2014.

11. Cherubini, F., G. Guest, and A.H. Strømman, Application of probability distributions to the modeling of biogenic CO2 fluxes in life cycle assessment. GCB Bioenergy, 2012. 4(6): p. 784-798.

12. Reisinger, A. and S. Ledgard, Impact of greenhouse gas metrics on the quantification of agricultural emissions and farm-scale mitigation strategies: a New Zealand case study. Environmental Research Letters, 2013. 8(2): p. 025019. 
13. Cherubini, F., R.M. Bright, and A.H. Strømman, Global climate impacts of forest bioenergy: what, when and how to measure? Environmental Research Letters, 2013. 8(1): p. 014049.

14. Edwards, M.R. and J.E. Trancik, Climate impacts of energy technologies depend on emissions timing. Nature Clim. Change, 2014. 4(5): p. 347-352.

15. Ledgard, S.F. and A. Reisinger, Implications of alternative greenhouse gas metrics for life cycle assessments of livestock food products, in 9th International Conference LCA of Food. 2014: 8-10 October 2014, San Francisco, USA.

16. Jolliet, O., et al., Global guidance on environmental life cycle impact assessment indicators: findings of the scoping phase. The International Journal of Life Cycle Assessment, 2014. 19(4): p. 962-967.

17. Frischknecht, R., et al., Global guidance on environmental life cycle impact assessment indicators: progress and case study. The International Journal of Life Cycle Assessment, 2016. 21(3): p. 429-442.

18. Tanaka, K., et al., Emission metrics under the $2{ }^{\circ} \mathrm{C}$ climate stabilization target. Climatic Change, 2013. 117(4): p. 933-941.

19. Huijbregts, M.A.J., S. Hellweg, and E. Hertwich, Do We Need a Paradigm Shift in Life Cycle Impact Assessment?Environmental Science \& Technology, 2011. 45(9): p. 3833-3834.

20. Fuglestvedt, J.S., et al., Transport impacts on atmosphere and climate: Metrics. Atmospheric Environment, 2010. 44(37): p. 4648-4677.

21. Tanaka, K., G.P. Peters, and J.S. Fuglestvedt, Policy Update: Multicomponent climate policy: why do emission metrics matter? Carbon Management, 2010. 1(2): p. 191197.

22. Tol, R.S.J., et al., A unifying framework for metrics for aggregating the climate effect of different emissions. Environmental Research Letters, 2012. 7(4): p. 044006.

23. Shine, K., The global warming potential - the need for an interdisciplinary retrial. Climatic Change, 2009. 96(4): p. 467-472.

24. Joos, F., et al., Carbon dioxide and climate impulse response functions for the computation of greenhouse gas metrics: a multi-model analysis. Atmos. Chem. Phys., 2013. 13: p. 2793-2825.

25. Peters, G.P., et al., The integrated global temperature change potential (iGTP) and relationships between emission metrics. Environmental Research Letters, 2011. 6(4): p. 044021.

26. Shine, K., et al., Alternatives to the Global Warming Potential for Comparing Climate Impacts of Emissions of Greenhouse Gases. Climatic Change, 2005. 68(3): p. 281302. 
713

714

715

716

717

718

719

720

721

722

723

724

725

726

727

728

729

730

731

732

733

734

735

736

737

738

739

740

741

742

743

744

745

27. Azar, C. and D.J.A. Johansson, On the relationship between metrics to compare greenhouse gases - the case of IGTP, GWP and SGTP. Earth Syst. Dynam., 2012. 3: p. $139-147$

28. Johansson, D., Economics- and physical-based metrics for comparing greenhouse gases. Climatic Change, 2012. 110(1): p. 123-141.

29. Unger, N., Short-lived non-CO2 pollutants and climate policy: fair trade?

30. Sterner, E., D.A. Johansson, and C. Azar, Emission metrics and sea level rise. Climatic Environmental Science \& Technology, 2010. 44(14): p. 5332-5333. Change, 2014: p. 1-17.

31. Shine, K.P., et al., Metrics for linking emissions of gases and aerosols to global precipitation changes. Earth Syst. Dynam. Discuss., 2015. 6(1): p. 719-760.

32. Reisinger, A., M. Meinshausen, and M. Manning, Future changes in global warming potentials under representative concentration pathways. Environmental Research Letters, 2011 . 6(2): p. 024020.

33. Shine, K.P., et al., Comparing the climate effect of emissions of short-and long-lived climate agents. Philosophical Transactions of the Royal Society A: Mathematical, Physical and Engineering Sciences, 2007. 365(1856): p. 1903-1914.

34. Jørgensen, S., M. Hauschild, and P. Nielsen, Assessment of urgent impacts of greenhouse gas emissions - the climate tipping potential (CTP). The International Journal of Life Cycle Assessment, 2014. 19(4): p. 919-930.

35. Allen, M., Short-Lived Promise? The Science and Policy of Cumulative and ShortLived Climate Pollutants, in Oxford Martin Policy Paper. 2015. p. 26; http://www.oxfordmartin.ox.ac.uk/publications/view/1960.

36. Allen, M.R., et al., New use of global warming potentials to compare cumulative and short-lived climate pollutants. Nature Clim. Change, 2016. advance online publication.

37. Pierrehumbert, R.T., Short-Lived Climate Pollution. Annual Review of Earth and Planetary Sciences, 2014. 42(1): p. 341-379.

38. Shoemaker, J.K., et al., What Role for Short-Lived Climate Pollutants in Mitigation Policy? Science, 2013. 342(6164): p. 1323-1324.

39. Fuglestvedt, J.S., et al., Climate implications of $G W P$-based reductions in greenhouse gas emissions. Geophysical Research Letters, 2000. 27(3): p. 409-412.

40. Smith, S.M., et al., Equivalence of greenhouse-gas emissions for peak temperature limits. Nature Clim. Change, 2012. 2(7): p. 535-538.

41. Daniel, J., et al., Limitations of single-basket trading: lessons from the Montreal Protocol for climate policy. Climatic Change, 2012. 111(2): p. 241-248.

42. Reisinger, A., et al., Uncertainties of global warming metrics: $\mathrm{CO} 2$ and CH4. Geophysical Research Letters, 2010. 37(14): p. L14707. 
43. Randall, D.A.e.a., Climate Models and Their Evaluation Climate Change 2007: The Physical Science Basis, ed. S.S.e. al. 2007, Cambridge, United Kingdom and New York, NY, USA: Cambridge University Press.

44. Allen, M.R. and T.F. Stocker, Impact of delay in reducing carbon dioxide emissions. Nature Clim. Change, 2014. 4(1): p. 23-26.

45. Solomon, S., et al., Persistence of climate changes due to a range of greenhouse gases. Proceedings of the National Academy of Sciences, 2010. 107(43): p. 18354-18359.

46. Shindell, D.T., et al., Improved Attribution of Climate Forcing to Emissions. Science, 2009. 326(5953): p. 716-718.

47. Boucher, O., et al., The indirect global warming potential and global temperature change potential due to methane oxidation. Environmental Research Letters, 2009. 4(4): p. 044007.

48. Sitch, S., et al., Indirect radiative forcing of climate change through ozone effects on the land-carbon sink. Nature, 2007. 448(7155): p. 791-794.

49. Gillett, N.P. and D.H. Matthews, Accounting for carbon cycle feedbacks in a comparison of the global warming effects of greenhouse gases. Environmental Research Letters, 2010. 5(3): p. 034011.

50. Collins, W.J., et al., Global and regional temperature-change potentials for near-term climate forcers. Atmos. Chem. Phys., 2013. 13(5): p. 2471-2485.

51. Archer, D. and V. Brovkin, The millennial atmospheric lifetime of anthropogenic CO2. Climatic Change, 2008. 90(3): p. 283-297.

52. Ciais, P., et al., Carbon and other biogeochemical cycles, in Climate Change 2013: The Physical Science Basis. Contribution of Working Group I to the Fifth Assessment Report of the Intergovernmental Panel on Climate Change, T.F. Stocker, et al., Editors. 2013, Cambridge University Press: Cambridge, U.K., and New York, NY, USA.

53. Eby, M., et al., Lifetime of Anthropogenic Climate Change: Millennial Time Scales of Potential CO2 and Surface Temperature Perturbations. Journal of Climate, 2009. 22(10): p. 2501-2511.

54. Johansson, D.J.A., et al., Equilibrium climate sensitivity in light of observations over

55. Friedlingstein, P., et al., Persistent growth of $\mathrm{CO} 2$ emissions and implications for the warming hiatus. Nature Clim. Change, 2015. 5(5): p. 449-453. reaching climate targets. Nature Geosci, 2014. advance online publication.

56. Frame, D.J., A.H. Macey, and M.R. Allen, Cumulative emissions and climate policy. Nature Geosci, 2014. 7(10): p. 692-693.

57. Stocker, T.F., The Closing Door of Climate Targets. Science, 2013. 339(6117): p. 280282.

58. Bowerman, N.H.A., et al., The role of short-lived climate pollutants in meeting temperature goals. Nature Clim. Change, 2013. 3(12): p. 1021-1024. 
59. Cherubini, F., et al., Linearity between temperature peak and bioenergy $\mathrm{CO} 2$ emission rates. Nature Clim. Change, 2014. 4: p. 983-987.

60. Gillett, N.P., et al., Constraining the Ratio of Global Warming to Cumulative CO2 Emissions Using CMIP5 Simulations*. Journal of Climate, 2013. 26(18): p. 68446858.

61. Matthews, H.D., et al., The proportionality of global warming to cumulative carbon emissions. Nature, 2009. 459(7248): p. 829-832.

62. Smith, S.J. and A. Mizrahi, Near-term climate mitigation by short-lived forcers. Proceedings of the National Academy of Sciences, 2013. 110(35): p. 14202-14206.

63. Rogelj, J., et al., Disentangling the effects of CO2 and short-lived climate forcer mitigation. Proceedings of the National Academy of Sciences, 2014. 111(46): p. 16325-16330.

64. Shindell, D. and G. Faluvegi, Climate response to regional radiative forcing during the twentieth century. Nature Geosci, 2009. 2(4): p. 294-300.

65. Fry, M.M., et al., The influence of ozone precursor emissions from four world regions on tropospheric composition and radiative climate forcing. Journal of Geophysical Research: Atmospheres, 2012. 117(D7): p. D07306.

66. Berntsen, T., et al., Abatement of Greenhouse Gases: Does Location Matter? Climatic Change, 2006. 74(4): p. 377-411.

67. Aamaas, B., et al., Regional emission metrics for short-lived climate forcers from multiple models. Atmos. Chem. Phys., 2016. 16(11): p. 7451-7468.

68. Meinshausen, M., S.C.B. Raper, and T.M.L. Wigley, Emulating coupled atmosphereocean and carbon cycle models with a simpler model, MAGICC6-Part 1: Model description and calibration. Atmos. Chem. Phys., 2011. 11: p. 1417-1456.

69. Joshi, M.M., F.H. Lambert, and M.J. Webb, An explanation for the difference between twentieth and twenty-first century land-sea warming ratio in climate models. Climate Dynamics, 2013. 41(7-8): p. 1853-1869.

70. Rypdal, K., et al., Tropospheric ozone and aerosols in climate agreements: scientific and political challenges. Environmental Science \& Policy, 2005. 8(1): p. 29-43.

71. Unger, N., On the role of plant volatiles in anthropogenic global climate change. Geophysical Research Letters, 2014. 41(23): p. 2014GL061616.

72. Yu, H., et al., A multimodel assessment of the influence of regional anthropogenic emission reductions on aerosol direct radiative forcing and the role of intercontinental transport. Journal of Geophysical Research: Atmospheres, 2013. 118(2): p. 700-720.

73. Lund, M.T., et al., How much information is lost by using global-mean climate metrics? an example using the transport sector. Climatic Change, 2012. 113(3-4): p. 949-963. 
74. Bond, T.C., et al., Quantifying immediate radiative forcing by black carbon and organic matter with the Specific Forcing Pulse. Atmos. Chem. Phys., 2011. 11(4): p. 1505-1525.

75. Shindell, D.T., Evaluation of the absolute regional temperature potential. Atmos. Chem. Phys., 2012. 12(17): p. 7955-7960.

832

76. Shindell, D., et al., Simultaneously Mitigating Near-Term Climate Change and Improving Human Health and Food Security. Science, 2012. 335(6065): p. 183-189.

77. Elshout, P.M.F., et al., Greenhouse-gas payback times for crop-based biofuels. Nature Clim. Change, 2015. 5(6): p. 604-610.

78. Finkbeiner, M., Indirect land use change-Help beyond the hype?Biomass and Bioenergy, 2014. 62(0): p. 218-221.

79. Schmidt, J.H., B.P. Weidema, and M. Brandão, A framework for modelling indirect land use changes in Life Cycle Assessment. Journal of Cleaner Production, 2015. 99(0): p. 230-238.

80. Searchinger, T.D., et al., Fixing a Critical Climate Accounting Error. Science, 2009.

81. Cherubini, F., et al., Global spatially explicit CO2 emission metrics for forest

82. Levasseur, A., et al., Biogenic Carbon and Temporary Storage Addressed with

83. Guest, G., F. Cherubini, and A.H. Strømman, Global Warming Potential of Carbon

84. Jørgensen, S., M. Hauschild, and P. Nielsen, The potential contribution to climate

86. Lee, X., et al., Observed increase in local cooling effect of deforestation at higher

87. Juang, J.-Y., et al., Separating the effects of albedo from eco-physiological changes on scale forest cover changes in the MPI earth system model. Biogeosciences 2010. 7: p. 
865

866

867

868

869

870

871

872

873

874

875

876

877

878

879

880

881

882

883

884

885

886

887

888

889

890

891

892

893

894

895

896

897

898

899

900

901

89. Davin, E.L. and N. de Noblet-Ducoudré, Climatic Impact of Global-Scale Deforestation: Radiative versus Nonradiative Processes. Journal of Climate, 2010. 23(1): p. 97-112.

90. Bala, G., et al., Combined climate and carbon-cycle effects of large-scale deforestation. Proceedings of the National Academy of Sciences, 2007. 104(16): p. 6550-6555.

91. Swann, A.L., et al., Changes in Arctic vegetation amplify high-latitude warming through the greenhouse effect. Proceedings of the National Academy of Sciences, 2010. 107(4): p. 1295-1300.

92. O'Halloran, T.L., et al., Radiative forcing of natural forest disturbances. Global Change Biology, 2012. 18(2): p. 555-565.

93. Simmons, C.T. and H.D. Matthews, Assessing the implications of human land-use change for the transient climate response to cumulative carbon emissions. Environmental Research Letters, 2016. 11(3): p. 035001.

94. Arora, V.K. and A. Montenegro, Small temperature benefits provided by realistic afforestation efforts. Nature Geosci, 2011. 4(8): p. 514-518.

95. Randerson, J.T., et al., The Impact of Boreal Forest Fire on Climate Warming. Science, 2006. 314(5802): p. 1130-1132.

96. Jackson, R.B., et al., Protecting climate with forests. Environmental Research Letters, 2008. 3(4): p. 044006.

97. Zhao, K. and R.B. Jackson, Biophysical forcings of land-use changes from potential forestry activities in North America. Ecological Monographs, 2014. 84(2): p. 329353.

98. Mahmood, R., et al., Land cover changes and their biogeophysical effects on climate.

99. Luyssaert, S., et al., Land management and land-cover change have impacts of similar International Journal of Climatology, 2013. In Press: p. doi:10.1002/joc.3736. magnitude on surface temperature. Nature Clim. Change, 2014. 4(5): p. 389-393.

100. Li, Y., et al., Local cooling and warming effects of forests based on satellite observations. Nat Commun, 2015. 6.

101. Baldocchi, D. and S. Ma, How will land use affect air temperature in the surface boundary layer? Lessons learned from a comparative study on the energy balance of an oak savanna and annual grassland in California, USA. Tellus B, 2013. 65.

102. Betts, R.A., Offset of the potential carbon sink from boreal forestation by decreases in surface albedo. Nature, 2000. 408(6809): p. 187-190.

103. Shindell, D.T., et al., Spatial patterns of radiative forcing and surface temperature response. Journal of Geophysical Research-Atmospheres, 2015. 120(11): p. 5385 5403. 
902

903

904

905

906

907

908

909

910

911

912

913

104. Jones, A.D., W.D. Collins, and M.S. Torn, On the additivity of radiative forcing between land use change and greenhouse gases. Geophysical Research Letters, 2013. 40(15): p. 4036-4041.

105. Arneth, A., et al., From biota to chemistry and climate: towards a comprehensive description of trace gas exchange between the biosphere and atmosphere. Biogeosciences, 2010. 7(1): p. 121-149.

106. Carslaw, K.S., et al., Large contribution of natural aerosols to uncertainty in indirect forcing. Nature, 2013. 503(7474): p. 67-71.

107. Rogelj, J., et al., Probabilistic cost estimates for climate change mitigation. Nature, 2013. 493(7430): p. 79-83. 